\title{
A new root-knot nematode, Meloidogyne moensi n. sp. (Nematoda: Meloidogynidae), parasitizing Robusta coffee from Western Highlands, Vietnam
}

\author{
T. M. L. LE ${ }^{1,2}$, T. D. NGUYEN ${ }^{1,2}$, H. T. NGUYEN ${ }^{1,2,3}$, G. LIEBANAS ${ }^{4}$, T. A. D. NGUYEN ${ }^{2,4}$, Q. P. TRINH ${ }^{1,2, *}$ \\ ${ }^{1}$ Institute of Ecology and Biological Resources, Vietnam Academy of Sciences and Technology, 18 Hoang Quoc Viet, Cau Giay,

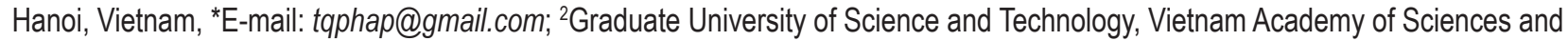 \\ Technology, 18 Hoang Quoc Viet, Cau Giay, Hanoi, Vietnam; ${ }^{N}$ Nematology Research Unit, Department of Biology, Ghent University, \\ K.L. Ledeganckstraat 35, 9000 Ghent, Belgium; 'Departamento de Biología Animal, Biología Vegetal y Ecología, Universidad de Jaén, \\ Campus 'Las Lagunillas' s/n, Edificio B3, 23071-Jaén, Spain
}

Article info

Received September 26, 2018

Accepted March 14, 2019

\section{Summary}

A new root-knot nematode, parasitizing Robusta coffee in Dak Lak Province, Western Highlands of Vietnam, is described as Meloidogyne moensi n. sp. Morphological and molecular analyses demonstrated that this species differs clearly from other previously described root-knot nematodes. Morphologically, the new species is characterized by a swollen body of females with a small posterior protuberance that elongated from ovoid to saccate; perineal patterns with smooth striae, continuous and low dorsal arch; lateral lines marked as a faint space or linear depression at junction of the dorsal and ventral striate; distinct phasmids; perivulval region free of striae; visible and wide tail terminus surrounding by concentric circles of striae; medial lips of females in dumbbell-shaped and slightly raised above lateral lips; female stylet is normally straight with posteriorly sloping stylet knobs; lip region of second stage juvenile ( $\mathrm{J} 2$ ) is not annulated; medial lips and labial disc of $\mathrm{J} 2$ formed dumbbell shape; lateral lips are large and triangular; tail of $\mathrm{J} 2$ is conoid with rounded unstriated tail tip; distinct phasmids and hyaline; dilated rectum. Meloidogyne moensi $\mathrm{n}$. sp. is most similar to $M$. africana, M. ottersoni by prominent posterior protuberance. Results of molecular analysis of rDNA sequences including the D2-D3 expansion regions of 28S rDNA, COI, and partial COII/16S rRNA of mitochondrial DNA support for the new species status.

Keywords: new species; coffee; root-knot nematode; Vietnam

\section{Introduction}

Coffee is one of the most important crops worldwide because of its economic value (Campos \& Villain, 2005; Waller et al., 2007). According to Wiryadiputra and Tran (2008), Vietnamese Robusta coffee growing area is one of the biggest Robusta coffee growing areas in the world. The Vietnamese coffee growing area is about 500000 hectares, and most of them are located in Western Highlands of Vietnam (Trinh et al., 2009). The quality of coffee plantations is crucial since any imperfection can affect the outcome (Wiryadiputra \& Tran, 2008). Several factors challenge the coffee production such as soil fertility, varietal choice, and most importantly is the presence of pathogens. One of the biotic agents that threatens coffee production is root-knot nematode. Root-knot nematodes, Meloidogyne spp., are distributed worldwide and parasitize a wide range of economically important crops, including coffee, that cause serious damages (Campos \& Villain, 2005; Perry et al., 2009; Souza, 2008; Waller et al., 2007). They are obligate parasites on the roots of thousands of plant species, including monocotyledonous and dicotyledonous, herbaceous, and woody plants (Perry et al., 2009). Root-knot nematode infection causes root galls, shoot chlorosis, stunted growth, nutrient deficiencies,

\footnotetext{
$\bar{*}$ - corresponding author
} 
and secondary infections by other pathogens (Souza, 2008).

To date, eighteen species of the genus Meloidogyne have been reported in the world, namely M. exigua Goldi, 1887, M. africana Whitehead, 1960, M. arabicida Lopez, 1989, M. arenaria (Neal, 1889) Chitwood, 1949, M. coffeicola Lordello and Zamith, 1960, M. daklakensis Trinh, Le, Nguyen, Nguyen, Liebanas and Nguyen, 2018, M. decalineata Whitehead, 1968, M. hapla Chitwood, 1949, M. incognita (Kofoid and White, 1919) Chitwood, 1949, M. inornata Lordello, 1956, M. izalcoensis Carneiro, Almeida, Gomes and Hernandez, 2005, M. javanica (Treub, 1885) Chitwood, 1949, M. kikuyensis de Grisse, 1960, M. konaensis Eisenback, Bernard and Schmitt, 1994, M. mayaguensis Rammah and Hirschmann, 1988, M. megadora Whitehead, 1968, M. oteifae Elmiligy, 1968, M. paranaensis Carneiro, Carneiro, Abrantes, Santos and Almeida, 1996 (Souza, 2008; Trinh et al., 2018). Root-knot nematodes are considered the most damaging plant parasitic nematode on coffee in Vietnam (Trinh et al., 2009; 2013; Wiryadiputra \& Tran, 2008). The coffee associated species, $M$. incognita, has been mainly documented in the country (Bell et al., 2018; Nguyen \& Nguyen, 2000; Trinh et al., 2009; 2013; Wiryadiputra \& Tran, 2008). Subsequently, four other Meloidogyne species have also been found in coffee plantations in Vietnam, namely M. exigua, M. coffeicola, M. hapla, and M. daklakensis (Bell et al., 2018; Trinh et al., 2013; Trinh et al., 2018).

Identification of root-knot nematodes species is becoming more important for designing an effective nematode management practices (Perry \& Moens, 2013). Root-knot nematode species are normally identified using morphological features and morphometrics of the female, the second-stage juveniles, and the male such as the structure of the labial region, stylet, basal knobs, and the perineal patterns of mature females (Blok \& Powers, 2009; Eisenback, 1985). Molecular approaches, that have been using in identification of Meloidogyne species, can strongly support morphological approaches (Carneiro et al., 2014; Charchar et al., 2008; Janssen et al., 2017; Hummrey-Pereira et al., 2014; Subbotin et al., 2006; Trinh et al., 2018).

During a survey on coffee in Dak Lak Provinces, Western Highlands of Vietnam, one small unknown root-knot nematode species with a posterior protuberance was collected from unusual galls from replanted coffee plantation. The survey revealed high infection rates of coffee roots caused by a root-knot nematode species which may pose a potential threat to coffee. Therefore, the objectives of this study were to describe the new root-knot nematode species, Meloidogyne moensi n. sp., using light microscopy and Scanning Election Microscopy (SEM) observations; assess the diagnostic value of morphological and molecular characters.

\section{Material and Methods}

\section{Nematode population}

Nematodes were extracted from root galls and soil samples of the rhizosphere of Robusta coffee that were collected from Cu M'gar
District, Dak Lak Province, Western Highlands, Vietnam.

\section{Morphological characterization}

Second-stage juveniles and males were extracted from soil samples using the decanting and modified Baermann tray method (Whitehead \& Hemming, 1965). Measurements were made on permanent slides by heat-killed nematodes after a fixation by TAF and ethanol-glycerin dehydration according to the method that was described by De Grisse, 1969. Females were dissected from root tissues under a stereo-microscope, using a scalpel and forceps. Perineal patterns of mature females were prepared following Hartman \& Sasser (1985) and mounted in lactophenol.

\section{Light microscopy (LM)}

All slides were observed under the compound light microscope Carl Zeiss Axio Lab.A1 (Carl Zeiss AG, Oberkochen, Germany). Measurements and pictures were taken using ZEN lite software with the support of ZEISS Axiocam ERc5s digital camera (Carl Zeiss AG, Oberkochen, Germany). Pencil drawings were obtained using an Olympus BX51 DIC Microscope equipped with a digital camera and a drawing tube. Illustrations were made using Illustrator CS3 based on pencil drawing, microphotographs, and SEM pics. Identification was based on the diagnostic key of Eisenback (1985), Hewlett \& Tarjan (1983), Jepson (1987), Karssen (2002), and Kazachenko \& Mukhina (2013). Furthermore, a comparison with other recently described species was also accomplished (Humphreys et al., 2014; Tao et al., 2017; Trinh et al., 2018).

\section{Scanning electron microscopy (SEM)}

After the examination and identification, some specimens in good condition were selected for observation under SEM following the protocol of Nguyen et al. (2017). The nematodes were hydrated in distilled water, dehydrated in a graded ethanol and acetone series, critical point dried, coated with gold, and observed using a Zeiss Merlin Scanning Electron Microscope (Carl Zeiss AG, Oberkochen, Germany).

\section{Molecular characterization}

DNA was extracted from individual second-stage juveniles using the protocol of Holterman et al. (2009). The DNA extracted crude was kept at $-70{ }^{\circ} \mathrm{C}$ until it was used. DNA crude of each specimen was amplified using the following sets of primers: for D2-D3 expansion regions of $28 \mathrm{~S}$ rDNA, forward primer D2-5'-ACAAGTACCGTGAGGGAAAGTTG-3' and reverse primer D3-5'-TCCTCGGAAGGAACCAGCTACTA-3' were used (De Ley et al., 1999); for the mtDNA cytochrome $c$ oxidase I (COI) genes, primers CoxiF/ Cox1R (Cox1-5'-TGGTCATCCTGAAGTTTATG-3'/Cox1R-5'-CTACAACATAATAAGTATCATG-3') were used (Kiewnick et al., 2014); for the mtDNA cytochrome $c$ oxidase II (COII) genes, primers C2F3 (5'-GGTCAATGTTCAGAAATTTGTGG-3') and 1108 (5-TACCTTTGACCAATCACGCT-3') were used (Powers and Harris, 1993). The PCR mixtures contained $25 \mu$ l Hotstat PCR Mas- 


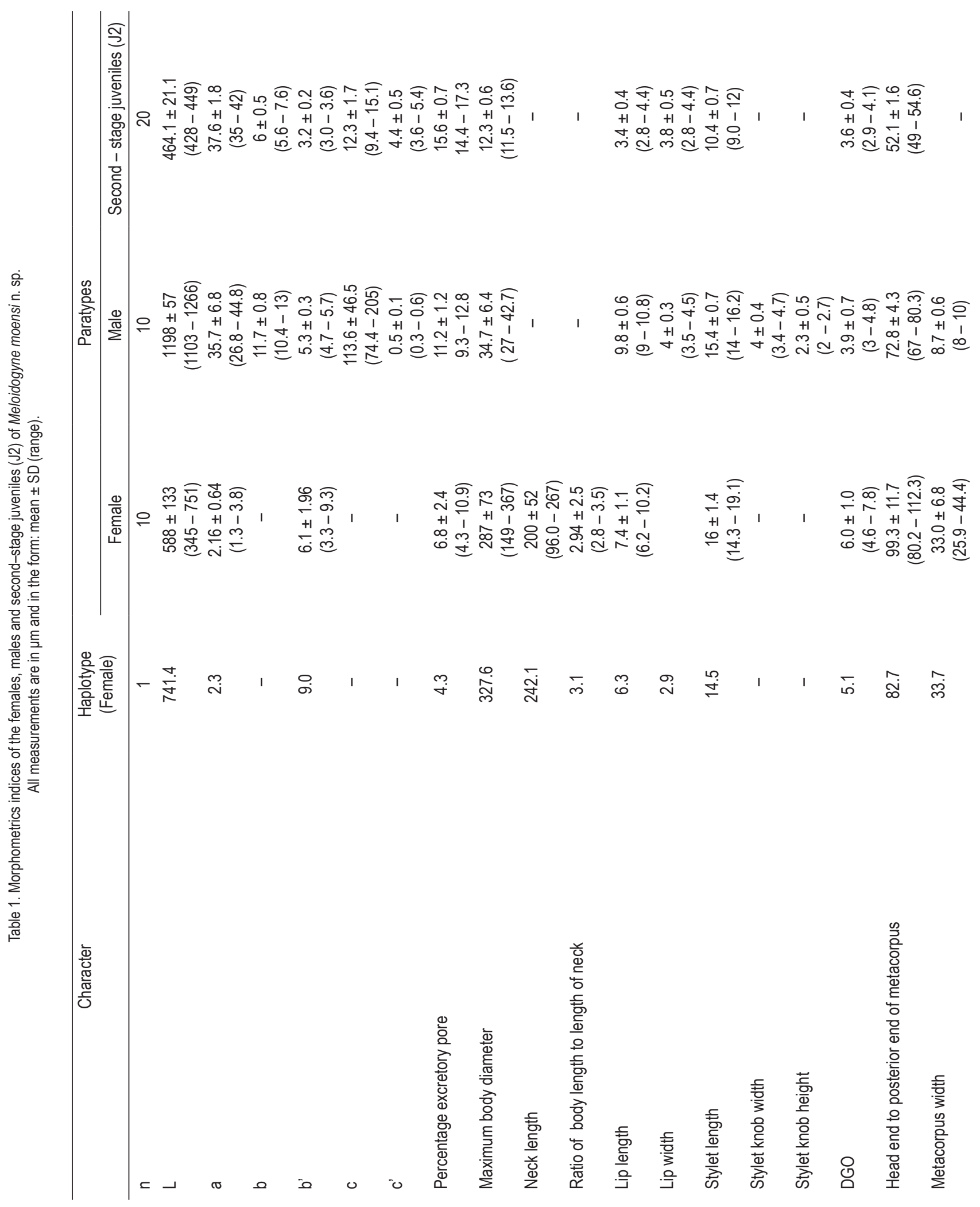




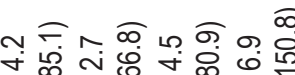

$\circ \underset{\infty}{\infty} \infty \overline{0}$

คำ

$+1 \quad 1+1 \quad 1+11+1$

$+1+1$

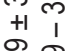

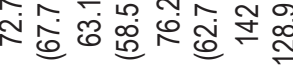

象

N

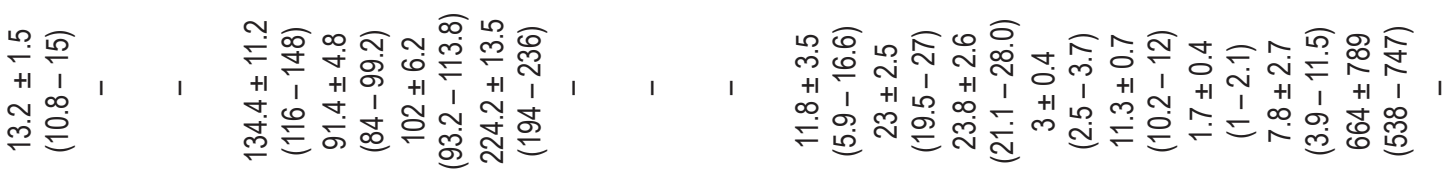

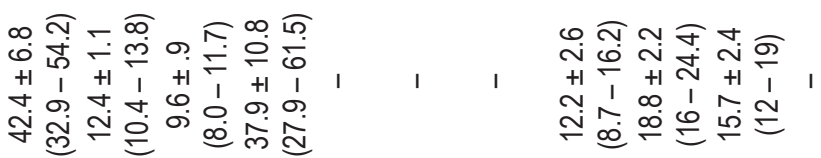

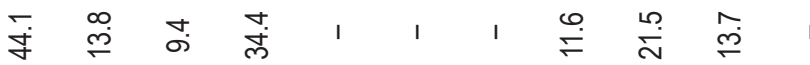

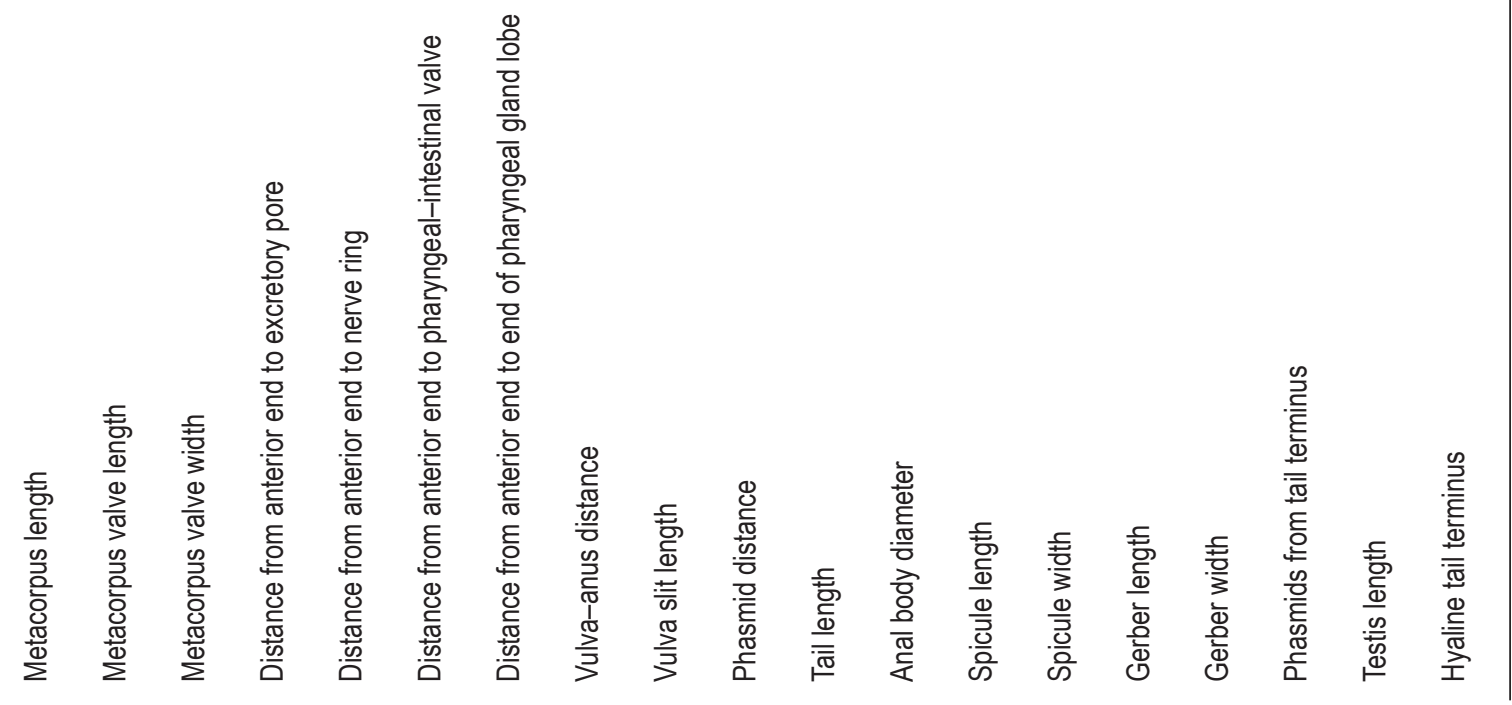



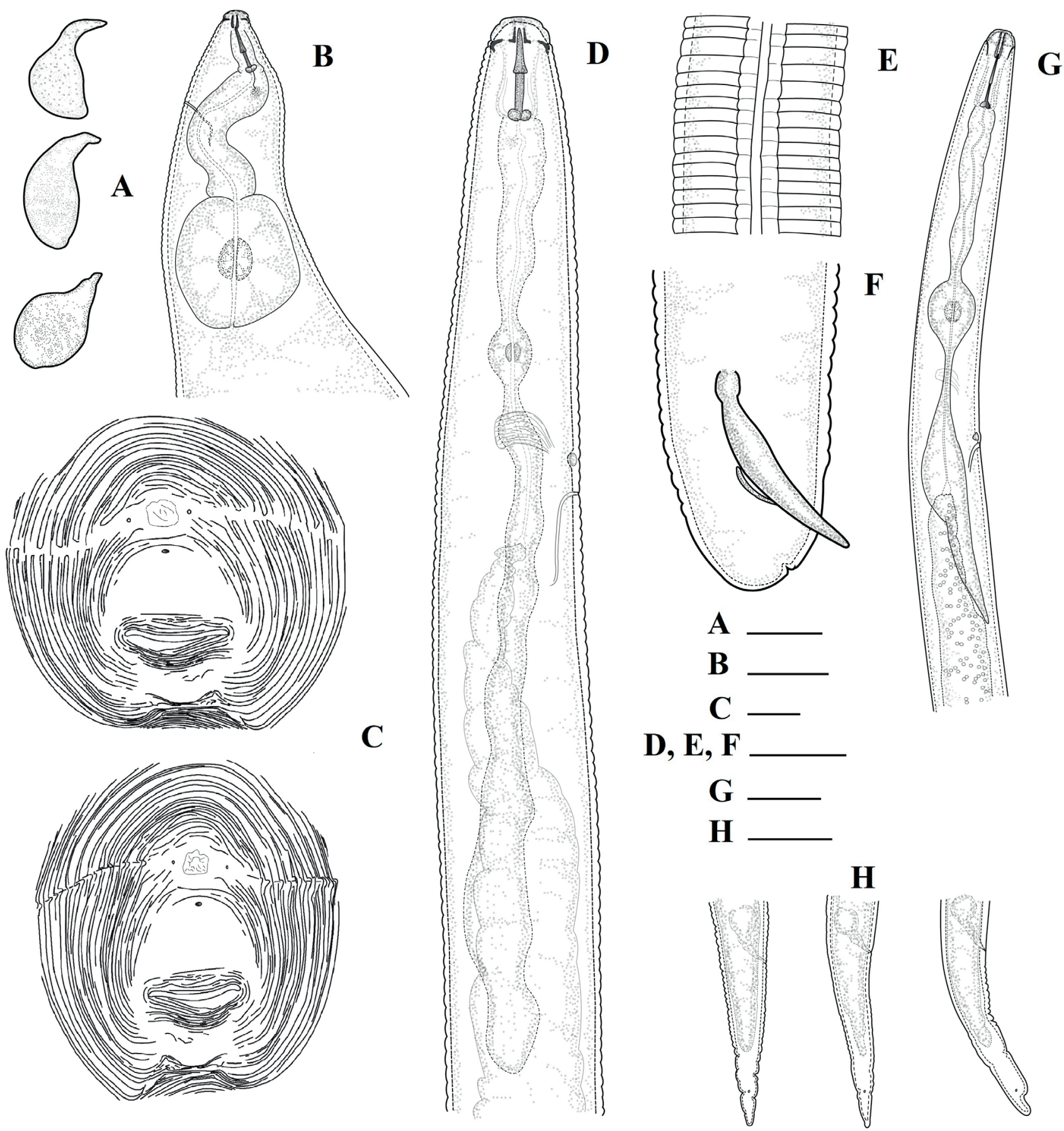

Fig. 1. Line drawing of Meloidogyne moensi n. sp. Female: (a) entire body variation; (b) anterior end; (c) perineal pattern. Male: (d) anterior region; (e) lateral field; (f) tail region. Second-stage juvenile: (g) anterior region; (h) tail variation. (Scale bar: (a): $200 \mu \mathrm{m} ;(\mathrm{b}, \mathrm{h}): 20 \mu \mathrm{m} ;(\mathrm{c}): 25 \mu \mathrm{m}$; (d, e, f): $15 \mu \mathrm{m} ;(\mathrm{g}): 10 \mu \mathrm{m})$.

termix (Promega, USA), $1 \mu \mathrm{M}$ forward and reverse primers, $5 \mu \mathrm{l}$ crude DNA-extract and sterile water up to a volume of $50 \mu \mathrm{l}$. The PCR reaction started at $95^{\circ} \mathrm{C}$ in 5 minute, followed by 35 cycles of $96^{\circ} \mathrm{C}$ in 35 seconds; $50^{\circ} \mathrm{C}$ in 30 seconds; $72^{\circ} \mathrm{C}$ in 45 seconds and the last step was $72^{\circ} \mathrm{C}$ in 3 minute. After electrophoresis of
$5 \mu \mathrm{l} \mathrm{PCR}$ product on $1.5 \%$ agarose gel with TAE buffer ( $1 \mathrm{~h}, 100 \mathrm{~V})$, the gel was stained with Gelred for $10 \mathrm{~min}$ and photographed under UV light. Sequence alignments were manually edited using ChromasPro software (ChromasPro 1.7.5, Technelysium Pty Ltd, Tewantin QLD, Australia). The datasets of D2-D3 expansion seg- 

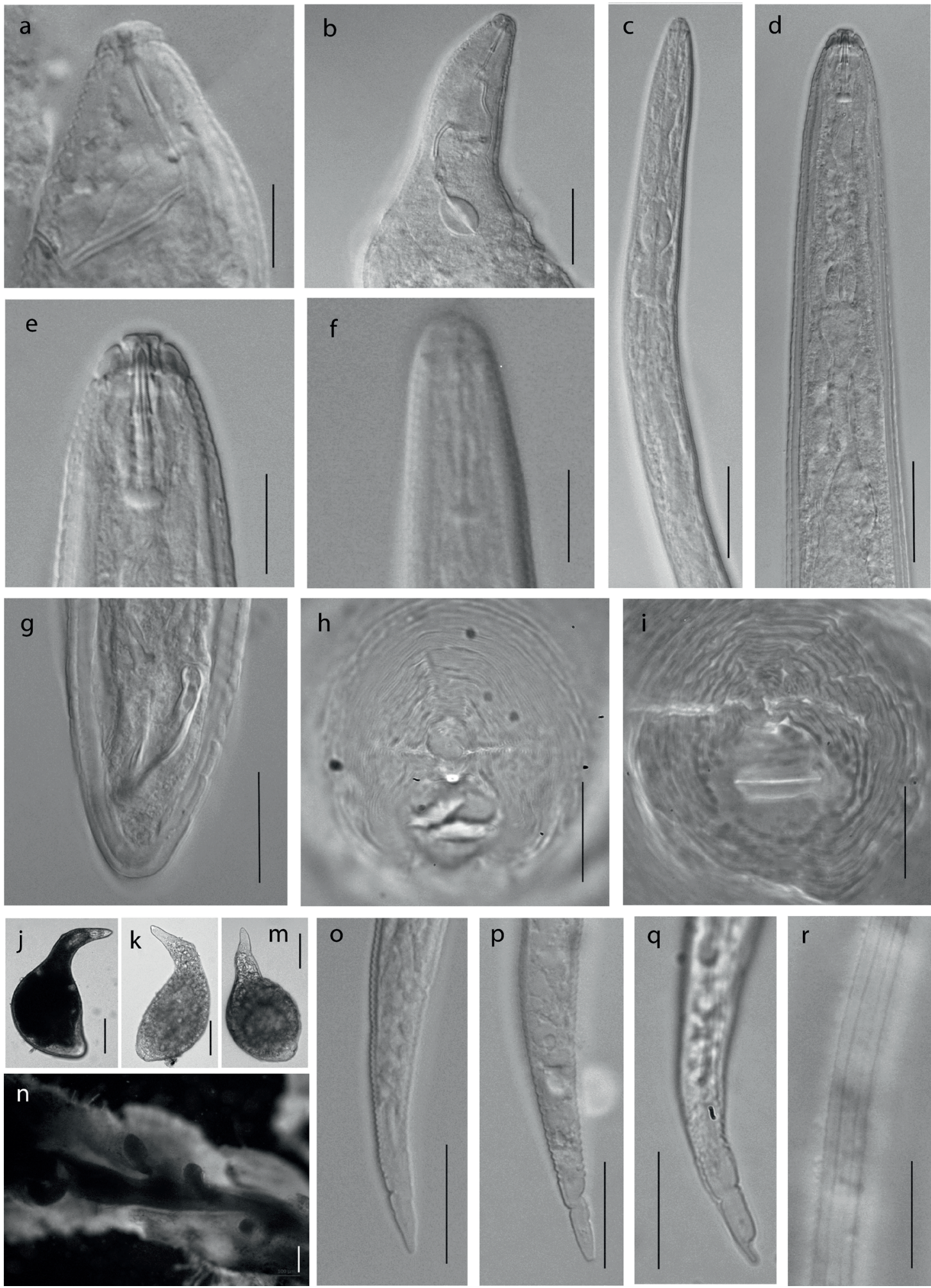

Fig. 2. Light microphotographs of Meloidogyne moensi $\mathrm{n}$. sp. Female: (a) anterior end; $(h$, i) perineal patterns; $(j, k, m)$ entire body variation. Male: $(d, e)$ anterior end; $(g)$ tail region. Second stage juvenile: $(c, f)$ anterior end; $(r)$ lateral field; $(0-q)$ tail variation. $(n)$ stained root shows females inside. (Scale bar: (f) $5 \mu \mathrm{m}$; (a, e, g, o-r) $10 \mu \mathrm{m}$; (b, c, d, h, i) $20 \mu \mathrm{m}$ ). 
ment of 28S rDNA, COI, and COII/16S-rRNA of mtDNA sequences were blasted on GenBank. The most similar sequences and recently added sequences of Meloidogyne species were selected for phylogenetic analyses. The sequence alignments were created using ClustalW in BioEdit v7.2.0 (Hall, 1999). The phylogenetic trees were built using Maximum Likelihood (ML) method in MEGA 6 software (Tamura et al., 2013). The best-fit models of base substitution were evaluated using MODELTEST in MEGA 6.0. Radopholus similis (JN091964) and Subanguina radicicola (LT714119) were chosen as outgroup for D2-D3 expansion regions of 28S rDNA sequences; Pratylenchus zeae (KU522440) was chosen as outgroup for COI of mitochondrial DNA sequences; Pratylenchus vulnus (NC020434) was chosen as outgroup for COII/16S-rRNA of mtDNA sequences.

\section{Ethical Approval and/or Informed Consent}

The conducted research is neither related to human nor animals use.

\section{Results}

Meloidogyne moensi n. sp. (Table 1, Fig. 1 - 3)

Type material: Vietnam: + Holotype (IEBR-Nema-5229/1), paratypes: $10 \hat{}{ }^{\lambda}, 109+$ and 20 juveniles (IEBR-Nema-5229/2-7) are deposited in the Nematode Collection of Nematology department in Institute of Ecology and Biological Resources (IEBR), Vietnam Academy of Sciences and Technology (VAST). Five female paratypes are deposited in Ghent University, K.L. Ledeganckstraat 35, Ghent, Belgium. The D2D3, COI and COII/16S-rDNA sequences are deposited in GenBank under accession number: (MF429805, MG825431), (MG825430, MG825432) and (MF429804, KY084500), respectively.

Type host: Robusta coffee (Coffea canephora Pierre ex A. Froehner)

\section{Site of infection: roots}

Type locality: Western Highlands, Dak Lak Province with GPS coordinates $12^{\circ} 47^{\prime} 06 \mathrm{~N}$ and $108^{\circ} 05^{\prime} 44^{\prime} \mathrm{E}$.

Pathology: Meloidogyne moensin. sp. causes inconspicuous galls or slight swellings on coffee roots (Fig. 2n). The presence of the nematodes was detected by the distortion of root system preventing absorption of nutrients which leads to stunting and chlorosis of the host plant. Coffee roots infected by Meloidogyne moensi $\mathrm{n}$. sp. had relatively small galls $(1-2 \mathrm{~mm}$ diam.). Each gall contained several females with egg mass inside the gall (Figs. 2n).

Etymology. The species is named after Prof. Dr. Maurice Moens as a recognization to his valuable help for nematology in Vietnam.

\section{Description}

Meloidogyne moensi n. sp.

Females. Body swollen with a small posterior protuberance, pearly white varying in shape, elongated from ovoid to saccate (Fig. 1a,2j, k, m). Neck prominent, bent at various angles to body (Figs. 1b,2b). Lip region slightly set off from rest of body (Fig. 2a); stoma slit-like, located in prominent ovoid pre-stomatal cavity, surrounded by pit-like openings of six inner labial sensilla; labial disc round, slightly raised above medial lips (Figs. 3a, b); labial cap and medial lips slightly raised above lateral lips; medial lips dumbbell-shaped (in SEM); lateral lips large, fused laterally with lip region; amphidial apertures oval shaped, located between labial disc and lateral lips. Cephalic framework strong, hexaradiate (Fig. 1b). Stylet short; cone base triangular and wider than shaft (Figs. $1 \mathrm{~b}$ and $2 \mathrm{a}$ ); stylet tip normally straight, sometimes slightly curved dorsally (Figs. $1 \mathrm{~b}$ and $2 \mathrm{a}$ ); stylet knobs three, oval and sloping posteriorly. Distance from base of stylet to dorsal pharyngeal gland orifice (DGO) 4.6 - $7.8 \mu \mathrm{m}$ long. Secretory-excretory pore located at level of procorpus, posterior to stylet knobs. Metacorpus rounded or oval, with oval-shaped valve; pharyngeal glands with one large dorsal lobe, variable in shape, position and size. Perineal pattern round to oval with continuous, smooth, distinct striae; lateral field marked as a faint space or linear depression junction of dorsal and ventral striate (Figs. 1 I.c; 2h, i and 3d, e); dorsal arch low, rounded, covering distinct vulva and tail terminus; phasmids large, distinct; vulva slit centrally located at unstriated area, nearly as wide as vulva-anus distance; perivulval region free of striae; tail tip visible, wide surrounded by concentric circles of striae; ventral striae concave, often free of striae (Fig. 1c, 2b, c, 5e, f).

Males. Body vermiform 1103-1266 $\mu \mathrm{m}$ long, anterior end tapering, posterior end bluntly rounded. Body annuli large, distinct. Lateral fields areolated with three incisures beginning near level of stylet knobs, two additional incisures starting near level of metacorpus (Figs. 1e and 3i). Head caps high and rounded, consisting of a large labial and two post-labial annuli, sometime with incomplete annuli (LM) (Figs. 1d, 2d, e). Lip region continuous to body; stoma slit-like, located in ovoid to hexagonal cavity, surrounded by pitlike openings of six inner labial sensilla; subventral and subdorsal lips fused to form median lips, each lips with two cephalic sensilla; lateral lips large, triangular, lower than labial disc and medial lips; posterior edge of one or both lateral lips separated with lip region, crescent-shaped (Fig. 3f); amphidial apertures elongated, located between labial disc and lateral lips. Stylet robust 14-16.2 $\mu \mathrm{m}$ long; cone pointed, smaller than shaft, slightly increasing in diameter posteriorly; knobs rounded, reniform, distinctly indented, backwardly sloping, transversely elongated, merging gradually with shaft (Figs. 1d and 2d, e). Distance from base of stylet to DGO 3-4.8 um long. Procorpus distinctly outlined; metacorpus ovoid, with a strong valve apparatus. Secretory-excretory pore distinct, located four to six annuli posterior to hemizonid. Testis one, 

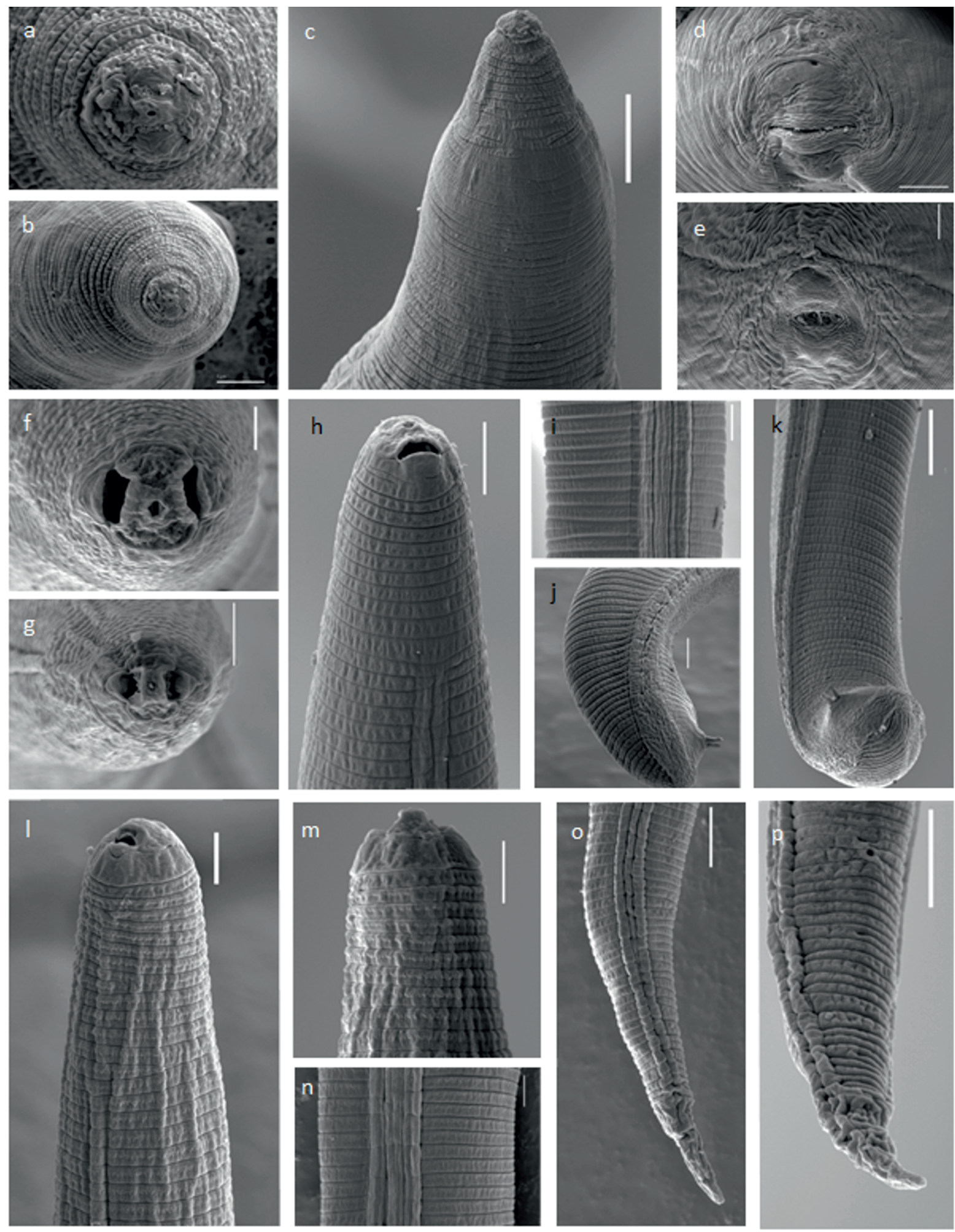

Fig. 3. Scanning electron microphotographs of Meloidogyne moensi n. sp. Female: (a, b) enface view; (c) anterior end, lateral view; (d, e) perineal pattern. Male: (f) enface view; (h) anterior end, lateral view; (i) lateral field; (j) tail region, lateral view; (k) tail region, ventral view. Second-stage juvenile: (g) enface view; (l) anterior end, lateral view; $(m)$ anterior end, ventral view; $(n)$ lateral field; $(0)$ tail region, lateral view; $(p)$ tail region, ventral view.

(Scale bar: (a, f, I, m, n) $2 \mu \mathrm{m} ;(\mathrm{b}, \mathrm{h}, \mathrm{i}, \mathrm{j}, \mathrm{o}, \mathrm{p}) 5 \mu \mathrm{m}$; (c, d, e, g, k) $10 \mu \mathrm{m})$. 
occupying $58 \%$ body cavity; spicules slightly curved ventrally with bluntly rounded terminus (Figs. 1f and $2 \mathrm{~g}$ ); gubernaculum short, crescent-shaped. Tail short; phasmids distinct, located at cloacal aperture level.

Second-stage juveniles (J2). Body slender, tapering to an elongated tail. Body annuli distinct, but fine. Lateral fields start near level of procorpus as two lines, third line start near metacorpus and quickly devide into four lines running entire length of body before gradually decrease to two lines that end near hyaline of tail; lateral field areolated whole body (Fig. 3n). Lip region narrower than body, weak and slightly set off (Figs. 1g and 2f). Under SEM, prestoma opening rounded, surrounded by small, pore-like openings of six inner labial sensilla; medial lips and labial disc dumbbell-shaped; lateral lips large, triangular, lower than labial disc and medial lips; cephalic sensilla not seen; amphidial apertures elongated, located between labial disc and lateral lips (Fig. $3 \mathrm{~g}$ ); lip region not annulated (Figs. 1g, 2h, 3l, m). Stylet slender; cone weakly expanding at junction with shaft; knobs small, oval shaped and backwardly sloping (Figs. 1g, 2o, p, q, r). Distance from stylet knobs to dorsal

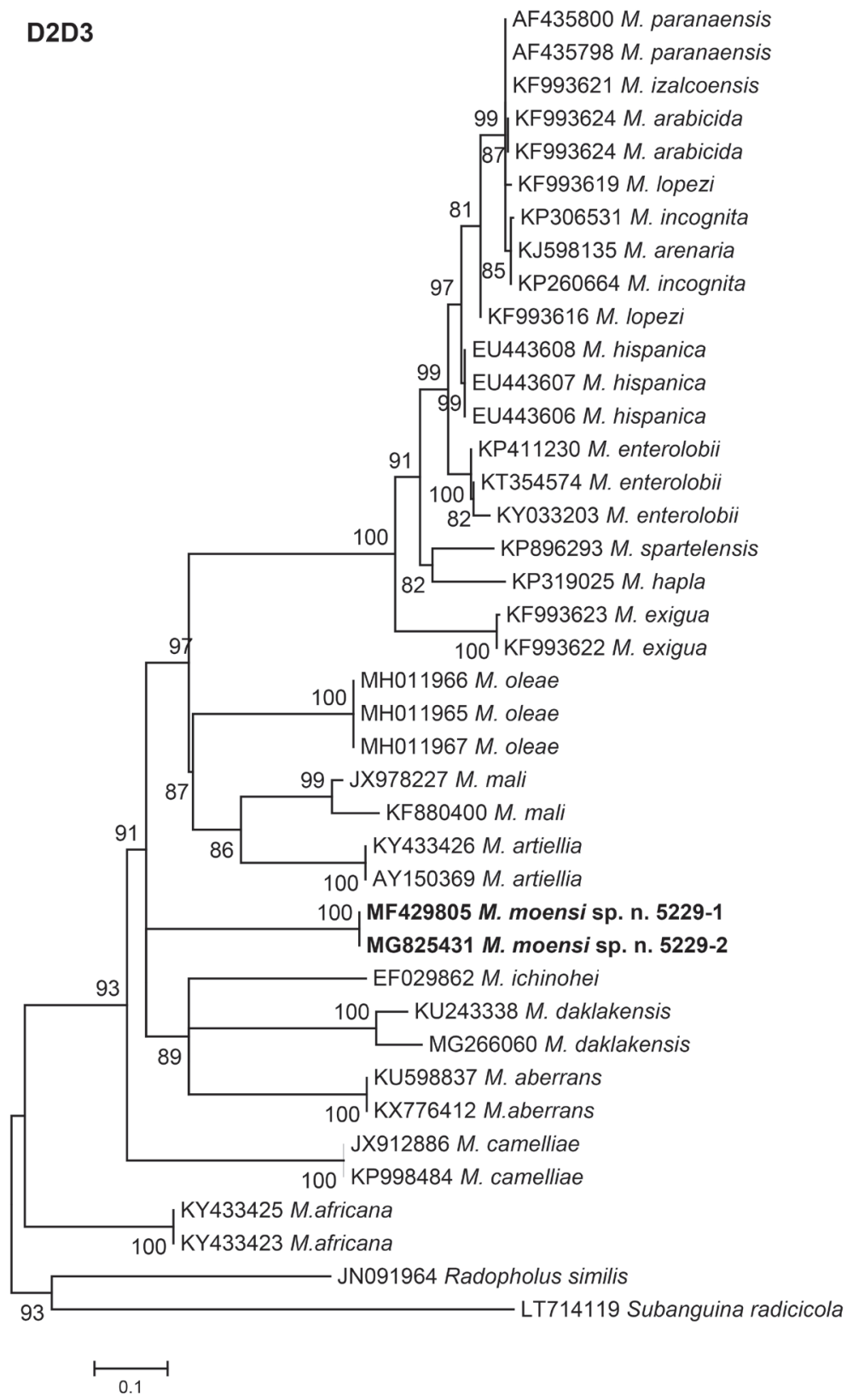

Fig. 4. Phylogenetic relationships of Meloidogyne moensi n. sp. with other Meloidogyne spp., based on D2-D3 of 28S-rDNA sequences using GTR+G model. Numbers on the left of nodes are bootstrap values for 1000 replications 
gland orifice 2.9-4.1 $\mu \mathrm{m}$ long. Procorpus faintly outlined; metacorpus broadly oval, valve large and heavily sclerotized; isthmus clearly defined; pharyngo-intestinal junction located posterior to level of secretory-excretory pore; gland lobe variable in length overlapping intestine ventrally. Secretory-excretory pore located posterior to hemizonid. Tail conoid with rounded unstriated tail tip (Figs. 1h, 3o, p); hyaline clearly defined (Fig. 20, p, q, r); rectum dilated; phasmids small, distinct.
Differential diagnosis

Females of Meloidogyne moensi n. sp. are characterized by the following characteristics: body swollen with a small posterior protuberance, elongated from ovoid to saccate; perineal patterns are rounded with smooth striae; dorsal arch is continuous and low; lateral lines appearing as a faint, discontinuous, or linear depression at junction of the dorsal and ventral striate; phasmids are distinct; perivulval region is free of striae; tail tip is wide, surrounded by concentric circles of striae; stylet tip is normally straight; stylet

\section{coxl}

100

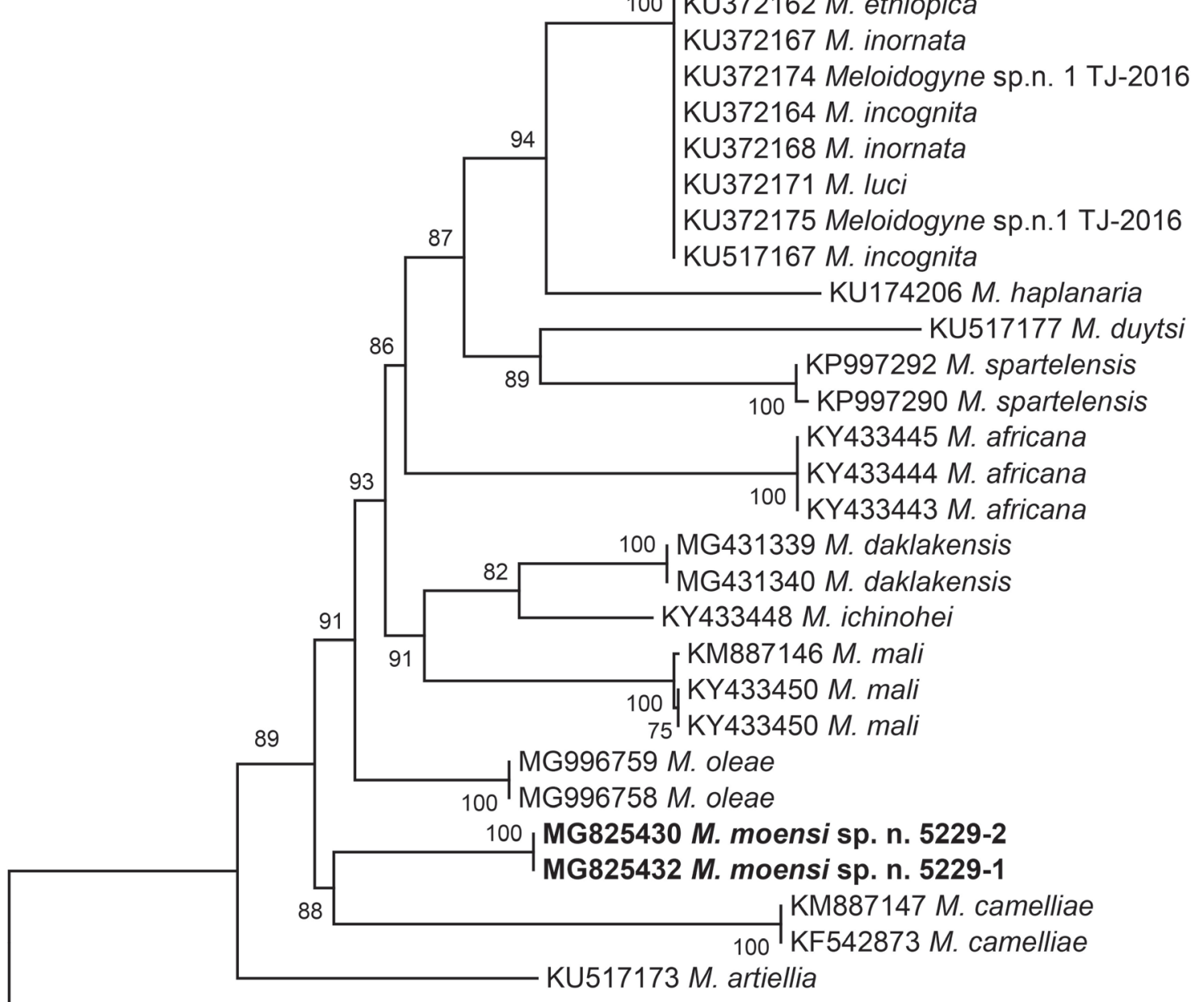

KX226436 Meloidogyne sp.n. 1 Al-2017

KU372165 M. incognita

KU372159 M. arenaria

KU372172 M. Iuci

KU372173 M. Iuci

KU360143 M. arenaria

KU372162 M. ethiopica

KU372167 M. inornata

KU372174 Meloidogyne sp.n. 1 TJ-2016

KU372164 M. incognita

KU372168 M. inornata

KU372171 M. Iuci

KU372175 Meloidogyne sp.n.1 TJ-2016

KU517167 M. incognita

KU174206 M. haplanaria

KU517177 M. duytsi

100 KP997290 M. spartelensis

KY433445 M. africana

KY433444 M. africana

KY433443 M. africana

KU522440 Pratylenchus zeae

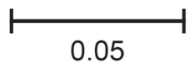

Fig. 5. Phylogenetic relationships of Meloidogyne moensi n. sp. with other Meloidogyne spp., based on COI sequences using TN93+G+I model. Numbers on the left of nodes are bootstrap values for 1000 replications 


\section{coxll-16S}

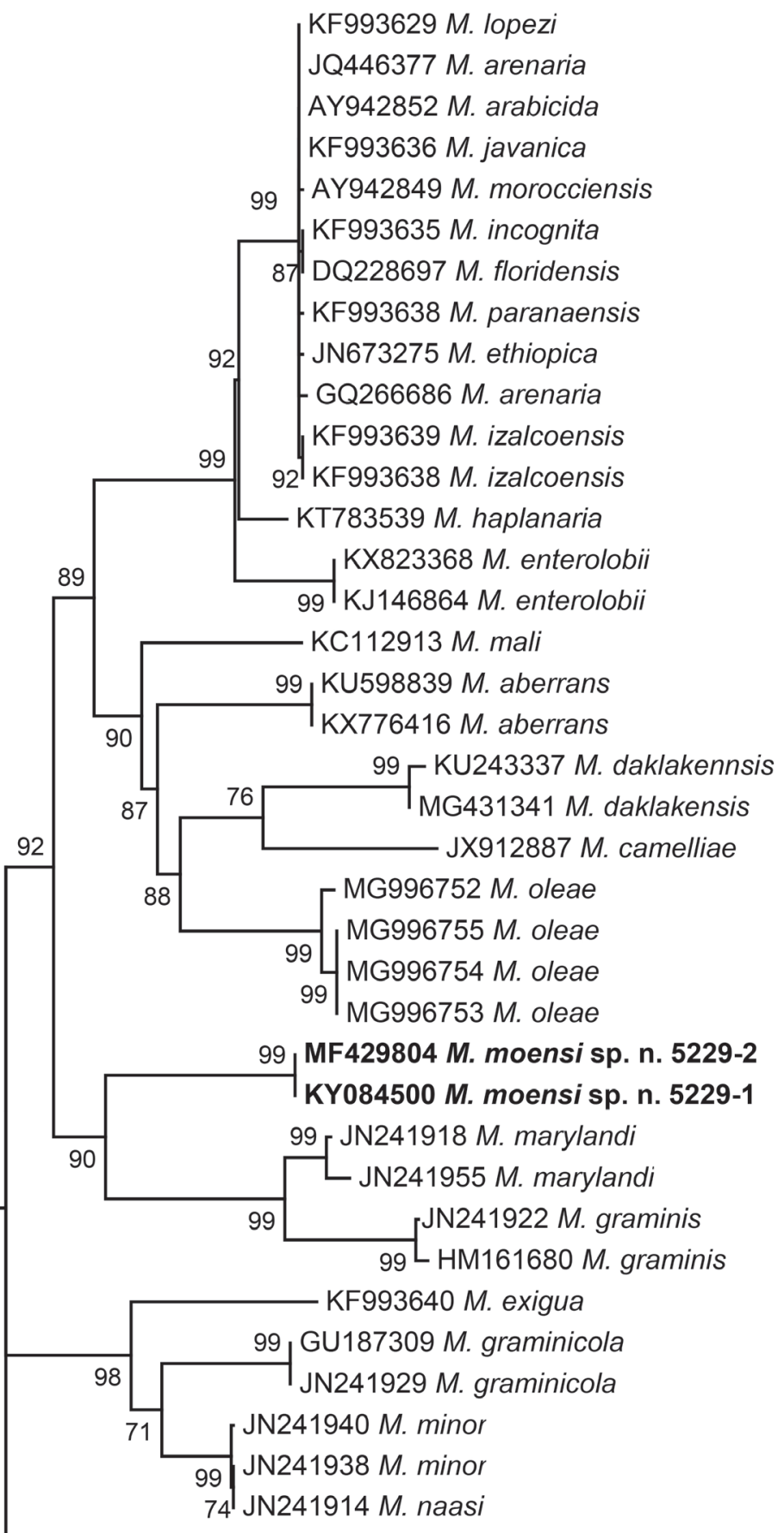

KF251138 Radopholus similis NC020434 Pratylenchus vulnus

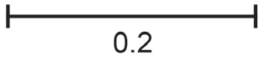

Fig. 6. Phylogenetic relationships of Meloidogyne moensi n. sp. with other Meloidogyne spp., based on COII-16S rRNA sequences using HKY+G+I model. Numbers on the left of nodes are bootstrap values for 1000 replications. 
knobs are oval-shaped and slope posteriorly. Second stage juveniles are characterized by lip region is not annulated; medial lips and labial disc fused to form dumbbell-shape; lateral lips are large, triangular, and lower than labial disc and medial lips; tail is conoid with rounded unstriated tail terminus; hyaline is clearly defined; dilated rectum; distinct phasmids.

Meloidogyne moensi n. sp. is most similar to M. acronea Coetzee, 1956, M. aberrans Tao, Xu, Yuan, Wang, Lin, Zhuo \& Liao, 2017, M. africana Whitehead, 1959, M. graminis Sledge and Golden, 1964) Whitehead, 1968, M. ichinohei Araki, 1992, M. marylandi Jepson and Golden, 1987, M. megadora Whitehead, 1968; and M. ottersoni Thorne, 1969 by prominent posterior protuberance and perineal patterns belong to group 3 (except for M. graminis that belong to group 5) according to Jepson (1987). However, they can be distinguished from each other by the following features.

Meloidogyne moensi n. sp. differs from $M$. acronea Coetzee, 1956 (Coetzee \& Helen, 1965) in the females by having perineal patterns not obscure vs extremely obscure, shorter body length, longer stylet length, smaller maximum body diameter; in the male by having shorter body length, shorter stylet length, larger "b" ratio, shorter spicule length; in the second-stage juveniles by having shorter body length, larger "a" ratio, larger "c" ratio (Table 2).

Meloidogyne moensi n. sp. differs from M. aberrans Tao, Xu, Yuan, Wang, Lin, Zhuo, \& Liao, 2017 in the females by having striae in perineal pattern (distinct and continuous vs extremely faint and broken), phasmids distinct vs phasmids not visible, shorter body length, smaller maximum body diameter, longer stylet length, shorter vulva-anus distance, smaller vulva slit length; in the males by having shorter body length, shorter stylet length, smaller $c$ value, shorter spicule length; in the juveniles by having shorter stylet length, larger "a" ratio, larger "b" ratio, larger "c" ratio (Table 2). Meloidogyne moensi n. sp. also differs from M. aberrans by D2D3 of $28 S$ rDNA sequences (25\% different), and COII/16S-rRNA sequences (37\% different).

Meloidogyne moensi n. sp. differs from M. africana Whitehead, 1959 (Jassen et al., 2017) in the females by having lateral field structure (lateral lines marked as a faint space or linear depression junction of the dorsal and ventral striate vs lateral fields are unmarked by incisures, but they present tiny, disordered striae), smaller maximum body diameter, longer stylet length; in the males by having smaller DGO, larger "a" ratio, smaller spicule length; in the second-stage juvenile by having smaller body width, smaller stylet length, and larger "a" ratio, shorter tail length (Table 2). Meloidogyne moensi n. sp. differs from M. africana by D2-D3 of $28 \mathrm{~S}$ rDNA sequences (23\% different), and COI sequences (20\% different).

Meloidogyne moensi n. sp. differs from M. graminis (Sledge and Golden, 1964) Whitehead, 1968, in the females by having longer stylet $(14.3-19.1$ vs $11.7-13.44 \mu \mathrm{m})$, lip region slightly set off vs not distinctly set off, cephalic framework strong vs cephalic framework indistinct, excretory pore located behind from stylet knobs vs located about on a level with knobs, perineal patterns with smooth striae, low arch vs perineal pattern with coarse striae, high arch, perineal patterns belong to group 3 vs group 5 according to Jepson (1987); in the males by having shorter body length (1103 - 1266 vs 1275 - $1734 \mu \mathrm{m})$, shorter stylet (14 - 16.2 vs $17.92-19.00 \mu \mathrm{m})$; larger "b" ratio (10.4 - 13 vs 6.42 - 8.2); in second-stage juveniles by having larger "a", "b" and "c" ratio (35 - 42 vs 28.77 - 33.99), $6 \pm 0.5$ (5.6 - 7.6 vs 2.10 - 2.95); (9.4 - 15.1 vs $5.71-6.78$ ), respectively. Meloidogyne moensi $\mathrm{n}$. $\mathrm{sp}$. can be distinguished from M. graminis by D2-D3 of $28 \mathrm{~S}$ rDNA sequences (27\% different), and COII/16S-rRNA sequences (35\% different).

Meloidogyne moensi n. sp. differs from M. ichinohei Araki, 1992 in the females by having perineal patterns with smooth and continuous striae vs striae extremely faint, broken and somewhat spaced, phasmids distinct vs phasmids small and obscure, lateral lines marked as a faint space or linear depression junction of the dorsal and ventral striate vs lateral lines absent, sometimes with lines of particles instead. smaller body length (345 - 751 vs 618.8 - $1018.8 \mu \mathrm{m})$, longer stylet length, shorter vulva-anus distance, shorter vulva slit length; males have smaller body length, shorter DGO; second-stage juveniles have smaller body width, shorter DGO (Table 2). Meloidogyne moensi n. sp. is different from $M$. ichinohei by D2-D3 of 28S rDNA sequences (19\% different), and $\mathrm{CO}$ sequences (15\% different).

Meloidogyne moensi n. sp. differs from M. marylandi Jepson and Golden, 1987 in the females by having perineal pattern with low dorsal arch vs squared dorsal arch, striae are smooth, continuous and closely spaced vs striae are coarse, wavy, and widely spaced, smaller body length ( 345 - 751 vs 525.1 - $923.2 \mu \mathrm{m}$ ), longer stylet length $(14.3$ - 19.1 vs $14.2-14.8 \mu \mathrm{m})$, longer DGO (4.6 - 7.8 vs $3.5-4.7 \mu \mathrm{m})$; the second-stage juveniles have smaller maximum body diameter (11.5 - 13.6 vs 13.6 - $17.1 \mu \mathrm{m})$, larger "a" ratio (35 - 42 vs 25.2 - 33.1), and shorter tail length (32.2 - 48.8 vs $52.5-68.4 \mu \mathrm{m})$. Meloidogyne moensi n. sp. also differs from $M$. myrylandi by D2-D3 of 28S rDNA sequences ( $27 \%$ different), and COIl/16S-rRNA sequences (30\% different).

Meloidogyne moensi n. sp. differs from M. megadora Whitehead, 1968 (Maleita et al., 2016) in the females by having perineal pattern with closely spaced, continuous, and smooth striae vs faint, often broken, widely spaced, shorter female body length, smaller female body width, shorter vulva-anus distance and vulva slit length; juveniles of $M$. moensi $n$. sp. differs from $M$. megadora by having longer DGO, larger "a" and "c" ratio. Males of $M$. moensi n. sp. differs from M. megadora by shorter stylet length, and shorter spicule length (Table 2).

Meloidogyne moensi n. sp. differs from M. ottersoni Thorne 1969 in the females by having perineal pattern with concave ventral striae vs perineal pattern with simple rounded striae, longer stylet length; in the juveniles by having smaller stylet length, larger "a" and "c" ratio (Table 2). 


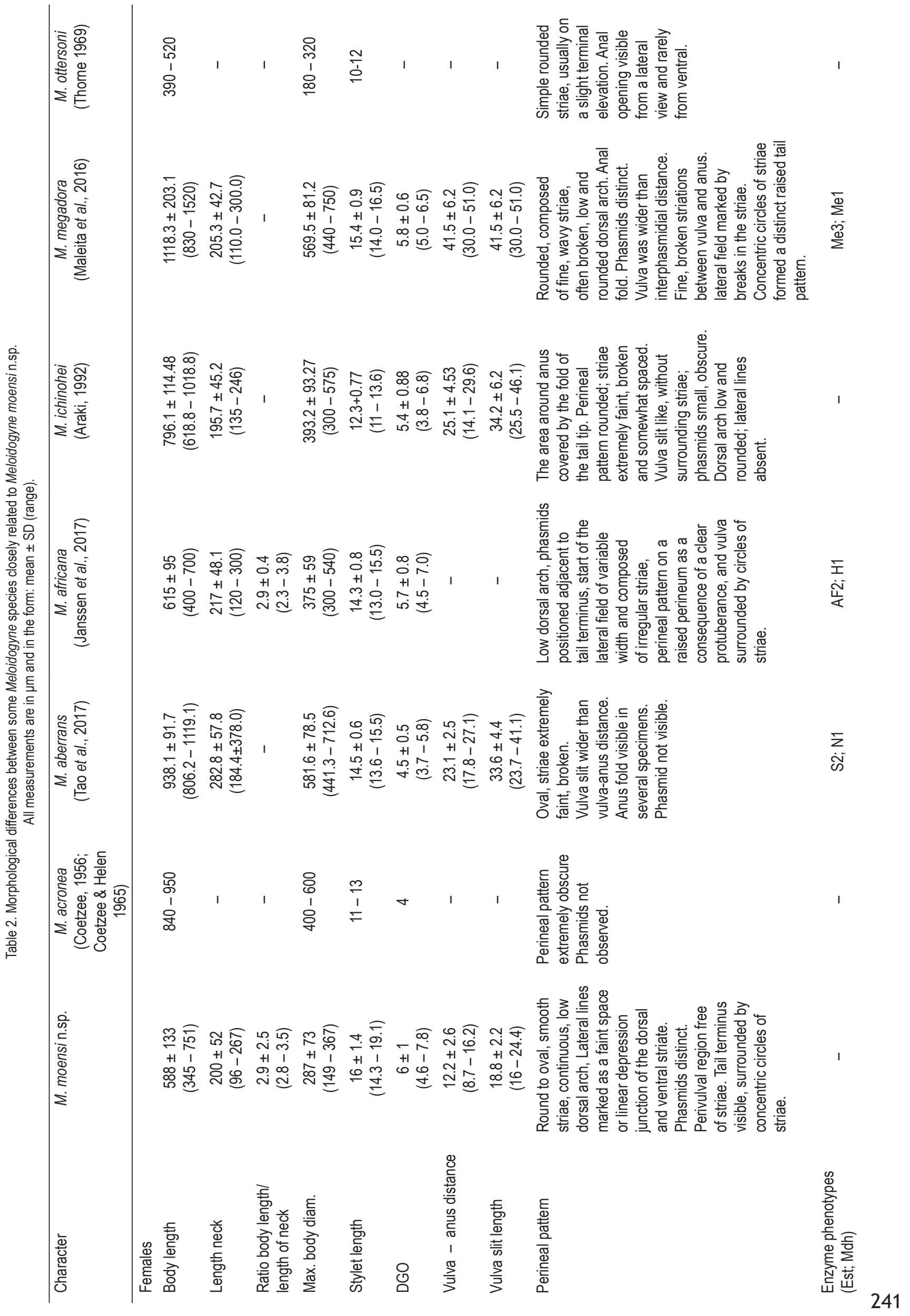




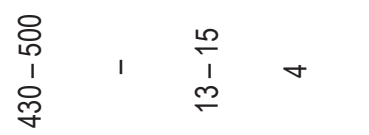

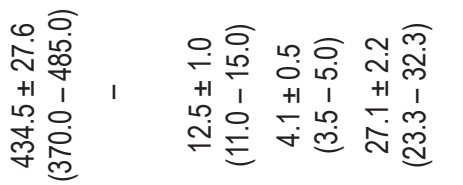

$\infty \sqrt[0]{10}$

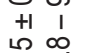

in

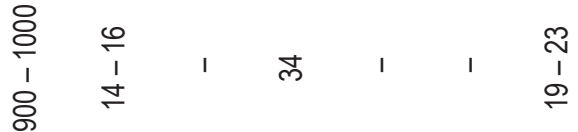

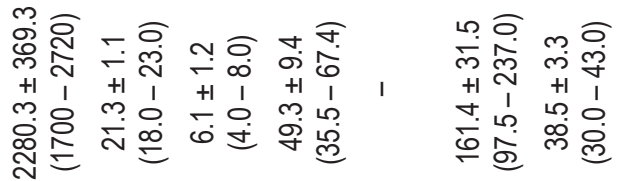

윰유

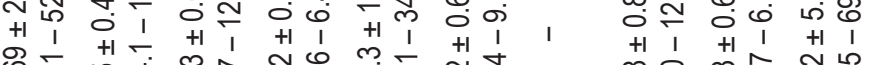

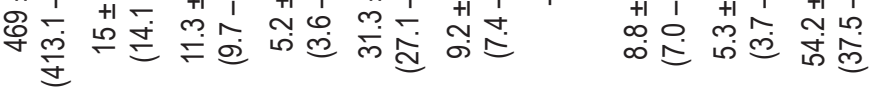

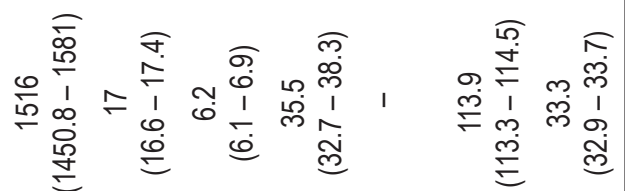

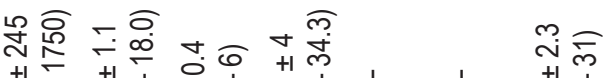

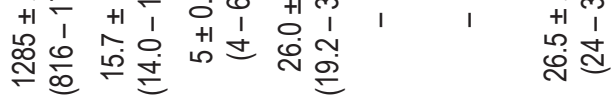

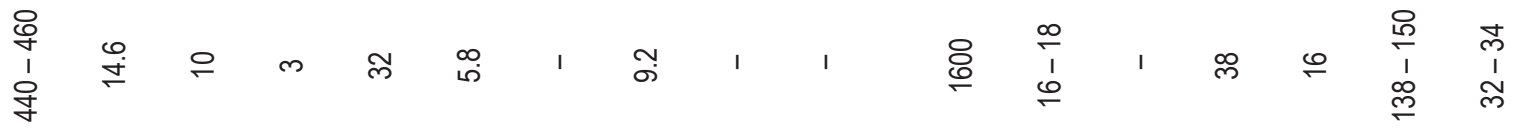

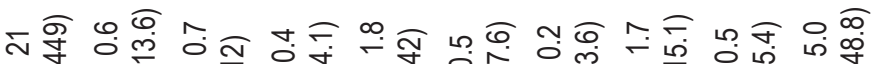

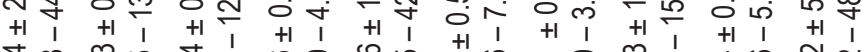

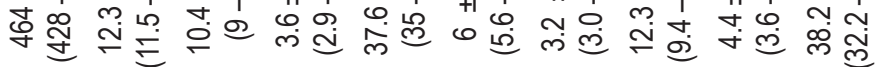

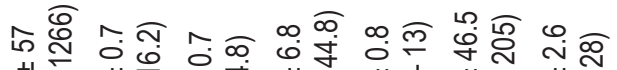

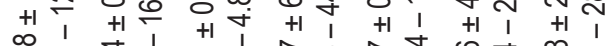
官完 
Molecular characterization

D2-D3 of 28S rDNA

Length of two D2-D3 of 28S rDNA sequences of $M$. moensi $n$. sp. were 788 bp ( $\% T=28.1 ; \% A=23.2 ; \% G=25.8 ; \% C=22.9)$. These sequences are $100 \%$ identical. The D2-D3 of $28 \mathrm{~S}$ rDNA sequences of Meloidogyne moensi $\mathrm{n}$. sp. are most similar to that in M. africanca (KY433425), M. ichinohei (EF029862) and M. aberrans (KX776412) (84\%, $80 \%$, and $79 \%$ similar, respectively). Phylogenetic relationship between related Meloidogyne species showed that $M$. africana was a sister of the clade formed by all Meloidogyne species. The sequences of Meloidogyne moensi $\mathrm{n}$. sp. were distinctly formed a separate clade with $100 \%$ bootstrap support. Meloidogyne moensi $\mathrm{n}$. sp. has a sister relationship to $M$. paranaensis, M. izalcoensis, M. arabicida, M. lopezi, M. hispanica, M. enterolobii, M. spartelensis, M. hapla, M. exigua, M. olae, $M$. mali, M. artiellia, M. ichinohei, M. daklakensis, and M. aberrans with $91 \%$ bootstrap support (Fig. 4).

\section{COI mtDNA}

Two obtained COI sequences were $100 \%$ similar, 562 bp long ( $\% \mathrm{~T}=47.7 ; \% \mathrm{~A}=28.3 ; \% \mathrm{G}=15.8 ; \% \mathrm{C}=8.2$ ). The blast result on Genbank showed that the new species is most similar to M. mali (KM887146; KY433450), M. ichinohei (KY433448), and M. africana (KY433444) $(86 \%, 82 \%$, and $80 \%$ similar, respectively). The phylogenetic tree $\mathrm{COI}$ sequences showed that the sequences of M. moensi n. sp. formed a separate clade with $100 \%$ bootstrap support. The sequences of Meloidogyne moensi n. sp. have a sister relationship to M. camelliae (88 \% bootstrap support) (Fig. 5).

\section{COII/16S-rRNA}

The obtained sequences of the region between the 3'end of COIl gene and the 5'portion of $16 \mathrm{~S}$ rRNA region was $526 \mathrm{bp}$ ( $\% \mathrm{~T}=54 ; \% \mathrm{~A}=34 ; \% \mathrm{G}=8 ; \% \mathrm{C}=4.1$ ). These sequences are $100 \%$ identical. The COII/16S-rRNA sequences of Meloidogyne moensi n. sp. were blasted using NCBI database, and the result showed that the COII/16S-rRNA sequences of Meloidogyne moensi $\mathrm{n}$. sp. were 74-80 \% similar compared to other Meloidogyne species. The sequences of Meloidogyne moensi n. sp. are most similar to M. marylandi (JN241955.1; JN241918.1), M. graminis (JN241922.1), and M. aberrans (KU598839) (80\%, $75 \%$, and $70 \%$ similar, respectively). The phylogenetic tree was created based on COII/16S-rRNA sequences showed a sister relationship of M. moensi n. sp. to M. marylandi and M. graminis with $90 \%$ bootstrap support. The sequences of Meloidogyne moensi n. sp. formed a separate clade with 99 \% bootstrap support (Fig. 6).

\section{Discussion}

In this study, a polyphasic approach including morphological observations, morphometry, and phylogeny of mitochondrial and ribosome DNA sequences were used to describe a new root-knot nematode from Robusta coffee in Western Highlands ofVietnam.
At the morphological level, body shape and size of females are useful to separate $M$. moensi n. sp. from species with prominent posterior protuberance, viz. $M$. acronea, $M$. aberrans, $M$. africana, M. megadora, M. ichinohei and M. ottersoni. According to Jepson (1987), perineal pattern characterisations are useful to separate Meloidogyne species into sub-group. The perineal pattern of this new species belongs to group 3 according to Jepson (1987) that can be clearly separated from other species in other groups. Measurements of the new species were also well-supported to differentiate this species from others (Jepson, 1987; Karssen, 2002; Perry et al., 2009).

Molecular characters are important tools for identification of nematodes, remains essential for accurate diagnosis of root-knot nematodes (Perry \& Moens, 2013). Furthermore, DNA-based methods can be applied to various stages in nematode development, separate individual species from mixed populations, and DNA voucher specimens, that have been stored for several years, can still be used efficiently (Onkendi \& Moleleki, 2013). The most commonly used sequences, such as 18S, 28S, and ITS rDNA or COI mtDNA regions, have been proven to be insufficient to distinguish some closely-related Meloidogyne species, making isozyme electrophoresis a prevalent choice in root-knot nematode identification, especially for the tropical group (Eisenback \& Triantaphyllou, 1985; Janssen et al., 2016). Nonetheless, the technique based on biochemical diagnosis, that is reliant on isozyme profiles, is only applicable to young adult females of Meloidogyne spp., and many results from different studies implied that polymorphic enzyme profiles exist. Additionally, the isozyme profiles are not available to all the valid species, making the identification using isozyme profiles more difficult (Esbenshade \& Triantaphyllou, 1985; Perry et al., 2009; Janssen et al., 2016). It is predicted that biochemical-based techniques, such as isozyme electrophoresis, will soon be replaced by PCR-based methods for many applications due to rapidly reducing cost, improvement of molecular techniques, and the finer resolution (Perry et al., 2009). Although isozyme charaterisation of the new species is not provided in this study due to the lack of facilities in Vietnam, as well as a degradation of machines for studying isozyme in our partner network; molecular analyses, morphological, and morphometric of M. moensi. n. sp. clearly define a new species that is distinct from all other Meloidogyne species.

Meloidogyne species that have a prominent posterior protuberance with an elevated perineum was previously assigned to the genus Hypsoperine (Sledge \& Golden, 1964). Later on, Hypsoperine was considered as a junior synonym of Meloidogyne (Araki, 1992; Eisenback \& Triantaphyllou, 1991; Jepson 1987; Luc \& Fortuner, 1988; Siddiqi, 2000; Whitehead, 1968). The phylogenetic tree inferred from $18 \mathrm{~S}$ sequences also showed that Hypsoperine was a junior synonym of Meloidogyne (Plantard et al., 2007). Our phylogenetic trees also placed those Meloidogyne species with a prominent posterior protuberance and elevated perineum, including M. moensis n. sp., M. aberrans, M. graminis, M. ichinohei, and M. africana M. megadora together with all Meloidogyne species. 
However, these species did not form a monophyletic group. In addition, M. moensis $\mathrm{n}$. $\mathrm{sp}$. is neither related to the exigua-chitwoodi-fallax group nor to the arenaria-javanica-incognita group.

The new species Meloidogyne moensi n. sp. was found on coffee, bringing the total number of coffee parasitic root-knot nematodes to 19 species in the world. This species was isolated from many samples of coffee with the symptoms such as root galls, stunting, and chlorosis; these symptoms implied a serious pathogen caused by the new root-knot nematode that need to be attended to prevent an outbreak in coffee growing areas.

\section{Acknowledgements}

The authors would like to thank the assistance of Research Technical Services of University of Jaén (Spain) for the SEM imaging. This research was supported by the following projects: the project code TN18/T07, the equipment from TWAS project (code: 14 246 RGA).

\section{Conflict of Interest}

Authors stated no conflict of interest.

\section{References}

ArakI, M. (1992): Description of Meloidogyne ichinohei n. sp. (Nematoda: Meloidogynidae) from Iris laevigata in Japan. Jap. J. Nematol., 22: 11 - 19

Bell, C.A., Atkinson, H.J., Andrade, A.C., Nguyen, H.X., Swibawa, I.G., Lilley, C., McCARTHY, J., URWIN, P. (2018): A high throughput molecular pipeline reveals the diversity in prevalence and abundance of Pratylenchus and Meloidogyne species in coffee plantations. Phytopathology, 108(5): 641 - 650

BLAXTeR, M.L. (2001): Molecular analysis of nematode evolution. In: Kennedy, M.W., HaRnetT, W. (Eds). Parasitic nematodes: molecular biology, biochemistry and immunology. Wallingford, UK: CABI Publishing, pp. $1-24$

BLOK, V.C., PowERs, T.O. (2009): Biochemical and molecular identification In: Perre, R. Moens, M., StaRr, J. (Eds) Root-knot Nematodes, Publisher: CABI Publishing, pp. $98-118$

BLouIN, M.S. (2002): Molecular prospecting for cryptic species of nematodes: mitochondrial DNA versus internal transcribed spacer. Int. J. Parasitol., 32, $527-531$

Campos, V.P., VILLAIN, L. (2005): Nematode parasites of coffee and cocoa. In: LUc, M., SIKORA, R.A., BRIDGE, J. (Eds) Plant parasitic nematodes in subtropical and tropical agriculture, Wallingford, UK: CABI Publishing, pp. $529-579$

Carneiro, R.M.D.G., Correa, V.R., Almeida, M.R.A., Gomes, A.C.M.M., Deimi, A.M., Castagnone-Sereno, P., Karssen, G. (2014): Meloidogyne luci n. sp. (Nematoda: Meloidogynidae) a root-knot nematode parasitising different crops in Brazil, Chile and Iran. Nematology, 16: $289-301$
Charchar, J.M., Elsenback, J.D., Charchar, M.J., Boiteux, M.E. (2008): Meloidogyne pisi n. sp. (Nematoda: Meloidogynidae), a root-knot nematode parasitizing pea in Brazil. Nematology, 10: $479-493$

CoetzeE, V. (1956): Meloidogyne acronea, a new species of rootknot nematode. Nature, 177: $899-890$

Coetzee, V., Helen, J.B. (1965): A Redescription of Hypsoperine acronea (Coetzee, 1956) Sledge \& Golden, 1964 (Nematoda: Heteroderidae), with a note on its biology and host specificity. Nematologica, 11: $480-484$

De GrISSE, A.T. (1969): Redescription ou modiphications de quelques techniques utilisées dans l'édude de nématodes phytoparasitaires [Redescription or modifications of some techniques used in the study of plant-parasitic nematodes]. Medelelingen Rijksfaculteit Landbouwwetenschappen Gent, 34: 315 - 359

De Ley, P., Felix, M.A., Frisse, L.M., Nadler, S.A., Stember, P.W., THOMAS, W.K. (1999): Molecular and morphological characterisation of two reproductive species with mirror image anatomy ( $\mathrm{Ne}$ matoda: Cephalobidae). Nematology, 1: $91-612$

EISENBACK, J.D. (1985): Detailed morphology and anatomy of second-stage juveniles, males, and females of the genus Meloidogyne (root-knot nematodes). In: SASSER, J.N., CARTER, C.C. (Eds.). An advanced treatise on Meloidogyne. Volume I. Raleigh, NC, USA: North Carolina State University Graphics, pp. 47 - 78

EISENBACK, J.D., TRIANTAPHYLLOU, H. (1991): Root-knot nematode: Meloidogyne sp. and races. In: NICKLE, W.R., (Ed) Manual of agricultural nematology. New York, US: Marcel Decker, pp. 191 - 274. HALL, T. (1999): BioEdit: a user-friendly biological sequence alignment editor and analysis program for Windows 95/98/NT. Nucleic Acids Symp. Ser., 41: 95 - 98

HARTMAN, K.M., SASSER, J.N. (1985): Identification of Meloidogyne species on the basis of differential host and perineal pattern morphology. In: Barker K.R Carter C.C Sasser J.N (Eds). An advanced treatise on Meloidogyne. Volume II. Raleigh, NC, USA: North Carolina State University Graphics, pp. 115 - 123.

Hewlett, T.E., TaRJAN, A.C. (1983): Monographs. Synopsis of the genus Meloidogyne Göldi, Nematropica, 1: $79-102$

Holterman, M., Karssen, G., van den Elsen, S., van Megen, H., BAKKER, J., HELDER, J. (2009): Small subunit rDNA-based phylogeny of the Tylenchida sheds light on relationships among some high-impact plantparasitic nematodes and the evolution of plant feeding. Phytopathology, 99: 227 - 235

Hugall, A., Moritz, C., Stanton, J., Wolstenholme, D.R. (1994): Low, but strongly structured mitochondrial DNA diversity in root knot nematodes (Meloidogyne). Genetics, 136: 903 - 912 Humphreys-Pereira, D.A., Flores-Chaves, L., Gomez, M., Salazar, L., Gomez-AlpizAR, L., Eluing, A.A. (2014): Meloidogyne lopezi n. sp. (Nematoda: Meloidogynidae), a new root-knot nematode associated with coffee (Coffea arabica L.) in Costa Rica, its diagnosis and phylogenetic relationship with other coffee- parasitising Meloidogyne species. Nematology, 16: 643-661

Janssen, T., Karssen, G., Topalović, O., Coyne, D., Bert, W. (2017): 
Integrative taxonomy of root-knot nematodes reveals multiple independent origins of mitotic parthenogenesis. PloS ONE, 12(3), e0172190. DOI: 10.1371/journal.pone. 0172190

Janssen, T., Karssen, G., Verhaeven, M., Coyne, D., Bert, W. (2016): Mitochondrial coding genome analysis of tropical root-knot nematodes (Meloidogyne) supports haplotype based diagnostics and reveals evidence of recent reticulate evolution. Sci. Rep., 6: 22591. DOI: 10.1038/srep22591

JEPSON, S.B. (1987): Identification of Root-Knot Nematodes (Meloidogyne species). Wallingford, UK, CAB International, $265 \mathrm{pp}$.

KARSSEN, G. (2002): The plant-parasitic nematode genus Meloidogyne Göldi, 1892 (Tylenchida) in Europe. The Netherlands, Brill, Leiden, $161 \mathrm{pp}$.

KAZACHENKo, I.P., MukHINA, T.I. (2013): Root-knot nematodes of genus Meloidogyne Göldi (Tylenchida: Meloidogynidae) of the world. Biol.-soil. Inst Dalnevost. Dept. of Ros. Acad. Science, Dalnevost. Feder. Univ. - Vladivostok, Dal'nauka, 306 pp.

Kiewnick, S., Holterman, M., van den Elsen, S., van Megen, H., Frey, J.E., HeLder, J. (2014): Comparison of two short DNA barcoding loci (COI and COII) and two longer ribosomal DNA genes (SSU \& LSU rRNA) for specimen identification among quarantine rootknot nematodes (Meloidogyne spp.) and their close relatives. Eur. J. Plant Pathol., 140, 97 - 110

Landa, B.B., Rius, J.E.P., Vovlas, N., CarneiRo, R.M., Maleita, C.M., de O. Abrantes I.M., Castillo, P. (2008): Molecular characterization of Meloidogyne hispanica (Nematoda, Meloidogynidae) by phylogenetic analysis of genes within the rDNA in Meloidogyne spp. Plant Dis., 92: 1104 - 1110

Luc, M., Maggenti, A.R., Fortuner, R. (1988): A reappraisal of Tylenchina (Nemata). 9. The family Heteroderidae Filip'ev \& Schuurmans Stekhoven, 1941. Revue Nématol., 11(2): $159-176$

Maleita, C.M., Almeida, A.F., Vovlas, N., Abrantes, I. (2016): Morphological, Biometrical, Biochemical, and Molecular Characterization of the Coffee Root-Knot Nematode Meloidogyne megadora. Plant Dis., 8: 1725 - 1734

Nguyen, T.D., Le T.M.L., Nguyen H.T., Nguyen T.A.D., Gracia L., TRINH Q.P. "Morphological and Molecular Characteristics of Pratylenchus haiduongensis sp. n., a New Species of Root-Lesion Nematodes Associated with Carrot in Vietnam. J. Nematol., 49(3): $276-285$

Nguyen, N.C., Nguyen, V.T. (2000): Plant parasitic nematodes in Vietnam. The Fauna of Vietnam Volume 4. Hanoi, Vietnam, Science and Technology Pub., 400 pp. (In Vietnamese)

ONKENDI, E.M., MoleLEKI, L.N. (2013): Distribution and genetic diversity of root-knot nematodes (Meloidogyne spp.) in potatoes from South Africa. Plant Pathol., 62: 1184 - 1192

PerRy, R.N., Moens, M., StaRr, J.L. (2009): Root-knot nematodes. Walingford, UK, CABI Publishing, 520 pp.

PerRy, R.N., Moens, M. (2013): Plant nematology. $2^{\text {nd }}$ Edition, Walingford, UK, CABI Publishing, $568 \mathrm{pp}$.

Plantard, O., Valette, S., Gross, M.F. (2007): The root-knot nematode producing galls on Spartina alterniflora belongs to the genus
Meloidogyne: Rejection of Hypsoperine and Spartonema spp. J. Nematol., 39(2): 127 - 132

Powers, T.O., HARRIS, T.S. (1993): A polymerase chain reaction method for identification of five major Meloidogyne species. J. Nematol., 25: $1-6$

SEINHORST, J.W. (1959): On the killing, fixation and transferring to glycerin of nematodes. Nematology, 8: $29-32$

SIDDIQI, M.R. (2000): Tylenchida: parasites of plants and insects, 2nd edition. Wallingford, UK, CABI Publishing, 848 pp.

Sledge, E.B., Golden, A.M. (1964): Hypsoperine graminis (Nematoda: Heteroderidae), a new genus and species of plant-parasitic nematode. P. Helminthol. Soc. Wash., 31: 83 - 88

SouzA RM (2008): Plant-parasitic nematodes of coffee. Berlin, Germany, Springer, $340 \mathrm{pp}$.

Subbotin, S.A., Sturhan, D., Chizhov, V.N., Vovlas, N., Baldwin, J.G. (2006): Phylogenetic analysis of Tylenchida Thorne, 1949 as inferred from D2 and D3 expansion fragments of the 28S rRNA gene sequences. Nematology, 8, $455-474$

Tamura, K., Stecher, G., Peterson, D., Fllipski, A., Kumar, S. (2013): MEGA 6: Molecular Evolutionary Genetics Analysis version 6.0. Mol. Biol. Evol., 30: 2725 - 2729

TaO, Y., Xu, C., Yuan, C., Wang, H., Lin, B., Zhuo, K., Liao, J. (2017): Meloidogyne aberrans sp. nov. (Nematoda: Meloidogynidae), a new root-knot nematode parasitizing kiwifruit in China. PIoS ONE 12(8), e0182627. DOI: 10.1371/journal.pone.0182627

THORNE, G. (1969): Hypsoperine ottersoni sp. n. (Nemata, Heteroderidae) infesting Canary grass, Phalaris arundinacea (L.) reed in Wisconsin. Proceedings of the Helminthological Society of Washington, 36: 98 - 102

Tigano, M.S., Carneiro, R.M.D.G., Jeyaprakash, A., Dickson, D.W.D., Adams, B.J.A. (2005): Phylogeny of Meloidogyne spp. based on $18 \mathrm{~S}$ rDNA and the intergenic region of mitochondrial DNA sequences. Nematology, 7: $851-862$

Trinh, P.Q., de la Pena, E., Nguyen, N.C., Nguyen, H.X., Moens, M. (2009): Plant-parasitic nematodes associated with coffee in Vietnam. Russ. J. Nematol., 17: $73-82$

Trinh, P.Q., Pham, T.K.D., NGuYen, N.C. (2013): Emerging Meloidogyne species (root-knot nematodes) threats to coffee in the Western Highlands in Vietnam. Proceedings of the 2nd VAST-KAST workshop on biodiversity and bio-active compounds, $313-318$

Trinh, P.Q., Le, T.M.L., Nguyen, T.D., Nguyen, H.T., Liebanas, G., NGUYEN, T.A.D. (2018): Meloidogyne daklakensis n. sp. (Nematoda: Meloidogynidae), a new root-knot nematode associated with Robusta coffee (Coffea canephora Pierre ex A. Froehner) in the Western Highlands, Vietnam. J. Helminthol., 93(2): 242 - 254. DOI: 10.1017/S0022149X1800020

Waller, J.M., BigGer, M., Hillocks, R.J. (2007): Nematodes Coffee pests, diseases and their management. Walingford, UK, CABI Publishing, $258-276$

WhiteHEAD, A.G. (1959): The root-knot nematodes of East Africa Meloidogyne africana n. sp., a parasite of arabica coffee (Coffea arabica L.). Nematologica, 4: 272 - 278 
Whitehead, A.G., Hemming, J.R. (1965): A comparison of some quantitative methods of extracting small vermiform nematode from soil. Ann. Appl. Biol., 55: 25 - 38

WhiteHEAD, A.G. (1968): Taxonomy of Meloidogyne (Nematodea: Heteroderidae) with descriptions of four new species. J. Zool., 31: $263-401$
WIRYADIPUTRA, S., Tran, L K (2008): Indonesia and Vietnam. In: SouzA, R.M. (Ed), Plant-parasitic nematodes of coffee. Netherlands: Springer, $277-292$

YE, W., ZENG, Y., KERNS, J. (2015): Molecular characterisation and diagnosis of root-knot nematodes (Meloidogyne spp.) from turfgrasses in North Carolina, USA. PIoS ONE 10(11), e0143556. DOI: 10.1371/journal.pone.0143556 